\title{
From Rural Labor to Urban Immigrant: Two Narratives and Approaches in Chinese Domestic Migration Study
}

\author{
Daming Zhou \\ Sun Yat-Sen University \\ Cao Yu \\ Sun Yat-Sen University
}

The narrative of rural labor was formed under the scenario of China's urban-rural dual social structure with certain limitations and bias. This paper reviews the domestic migration studies from both China and other countries and proposes to use the narrative and approach of urban immigrant instead of rural labor. Urban immigration should be seen as a process of social development led by the integration of urban immigrant and finally leading to the deconstruction of rural-urban duality. The change of narrative and approach from rural labor to urban immigrant has certain theoretical and countermeasure significance for understanding the process of population migration and urbanization in China.

Keywords: Rural Labor, Urban Immigrant, Rural-urban Duality

\section{BACKGROUND}

China has adopted the reform and opening-up policy for 3 decades since 1978 and achieved great progress in industrialization. By 2008, China's non-agricultural production shares reached as high as $88.7 \%$ of GDP, and urbanized population percentage rose from $17.9 \%$ in 1978 to $45.7 \%$ in 2008 , while the proportion of non-agricultural employment exceeded 50\% (National Census Bureau2009). However, the quality of urbanization in China is still quite low, and the proportion of non-agricultural employment is far lower than the proportion of non-agricultural production. The entire urbanization process is not in coordination with the progress of industrialization. Since the founding of the People's Republic of China, the state has made many mistakes and showed hesitations in promoting urbanization progress (Zhou 2009). In particular cases after the adoption of reform and opening-up policy, the state has imposed various restrictions on the flow of rural labor into cities and denied to treat rural migration population as equal to urban residents. The flow of urbanization population forms the pendulum mode of moving without settling down (Zhou 2005); the typical waves of migration labor have risen and fallen for many times. The state has long been in pursuit of economic development as primary task and neglecting the development of livelihood. This caused a long-term "industry focus" urban planning and development model. The supplies of livelihood infrastructure and public services did not keep up with the accelerated speed of urbanization. Consequently, this contradiction mostly affected the migration population (Zhou 2017). In 1980s, millions of migration labor flooded Guangzhou and neighboring regions. The media 
portrayed it as "the blind wave", and the government worried that the influx of people might cause "urban diseases" such as traffic jams, housing shortages and deterioration of public security. Therefore, throughout the 1980s, the population movement was sternly restricted, and several nationwide migration screening and repatriation actions aimed at rural labor were taken.

During the 1990s, the policies regarding population and migration became more regular, relevant departments successively set up migration population management and coordination institution, and issued a series of orders on hukou system, employment and social welfare. Since 2003, the "Central First Document " has repeatedly affirmed the status and contribution of migration labor as industrial workers in China's modernization progress, and said that it would "Push forward the reform of the hukou system in large and medium-sized cities, and ease the conditions for rural labor to enter cities for employment and residency" (Department of the State 2003). The outline of the eleventh "five-year plan" of the state pointed out that "for migrant workers who have stable occupation and residence in cities, conditions should be created to gradually declare them as urban residents". Beijing, Shanghai, Guangzhou, Shenzhen, Hangzhou, Zhengzhou, Wuhan and Shenyang have abolished their temporary residence permits and replaced them with residence permits and relevant hukou entry policies during the tenth and eleventh "five-year plan". Now, China is in the mature stage of industrialization and the economic structure is upgrading and adjusting for the future development. Promoting urbanization is "a major measure to promote the virtuous circle of national economy and the coordinated development of society". The state "encourages the rural population to settle in small and medium-sized cities and towns, while the megalopolis should start from the source of industrial structure adjustment and form the mechanism to control the overly rapid growth of population through economic measures" (Department of the State2006).

Since 1996, the national urbanization level has maintained an average annual growth rate of around $1.3 \%$, which indicates that China has been and will continue to be in the acceleration stage of urbanization (Northam1975, 65-67), and the urbanization process will gradually catch up with the pace of industrialization. Now, China's industrialization and urbanization has entered a new growth period of medium-term acceleration. The economic and social structure is expecting to undergo profound transformation, and the social structure change will enter the new growth period of breaking down the urban-rural dual structure ( $\mathrm{Li}$ and Chen 2009, 9-10). According to official prediction, China's urbanization proportion will be $64 \%$ to $75 \%$ by 2030 . This means $4-500$ million people will become permanent urban residents in the next 20 years. However, China has to solve the same problem left in the past; there are already 201 million migrants in cities who have not been converted to urban resident yet and hundreds of millions more are to come. If the migration population is not accepted as urban residents by now, a situation of trisection may occur after 30 years ( $\mathrm{Lu} 2009$ ). It is composed of 500 million urban residents, 500 million floating migrants who live and work in cities but do not enjoy the cover of cities' welfare, 500 million rural residents. Such situation may jeopardize China's social stability and national competency.

\section{RESEARCH REVIEW}

Many developed countries have been through hundreds of years processing industrialization and urbanization yet. Developing countries generally face the "time compression" (Li 2008) to complete the same process in a much shorter time period which brings many social problems along. China is experiencing this compression, and has formed a special urban-rural dual social structure. Development economics holds that the urban-rural dual transformation is the irresistible trend of economic and social development of any country. The mechanism of urban-rural dual social structure transformation is that urbanization promotes the transformation of agricultural society to industrial society, first by transferring more agricultural labor force to the employment of higher-income non-agricultural industries, and then promoting the transformation of social structure from rural society to urban society. We believe that forming the urban-rural dual economic and social structure is actually the process of migration. 


\section{Rural-urban Migration Study Outside China}

In early 19th century, Britain, ahead of any other countries, started its industrialization process, and transformed its rural labor to industrial labor in a century lasting progress. Ernst G. Ravenstein, a British geographer, has written twice about the migration base in the study of county level migration in Britain (Ravenstein1876, 1885). He determined migration absorption or dispersion by the gain and loss of population on county level, thus he mapped and summarized the laws of migration. In 1889, Ravenstein used the same method on more than 20 European and North American countries' population statistics and tried to prove that "different countries have similar migration patterns under the similar condition" (Ravenstein1889). Everett S. Lee (1996) summarized in his book "A Theory of Migration" that migration flow is positively correlated with economic prosperity. In the case of economic blooming, migration flow is bound to increase. In early 20th century, with the blooming of United States' economy, a large number of young farmers (mostly aged below 25) were pushed out of countryside and turned to cities for non-agricultural employment (Mercer 1965). These migrants were usually low-educated (with few college graduates) and low-skilled (or even unskilled) (Rose and Warshay 1957).

We believe that domestic migration, especially rural-urban migration, is the most obvious social phenomenon during the rapid industrialization era for every developed or developing country. However, developed countries may be able to "provide the opportunity for rural labors to pursue a decent life" (Mercer 1965), while the developing country were trapped to the dilemma of "infinite labor supply" (Lewis 1954). The large number of rural-urban migrants can improve income of the rural population, but the income maintains at a low level for quite a long time. This makes the gap between urban and rural and the urban-rural dual structure hard to overcome. Michael P. Todaro (1969) believes that rural-urban migration in developing countries is determined by the rural-urban "expected" income differential and the probability of finding an urban job. He divides the process of migration in developing countries into two stages: first, rural labors with little skills migrate to cities to find jobs in conventional sectors, and then after a period of efforts and adaptation (generation or generations), they find stable modern sector jobs. Half a century later, South Korea, Taiwan, and other developing countries and regions in East Asia successfully completed the transformation in this way. Rural residents could not only find stable jobs in cities, but, they also chose to return to rural areas for non-agricultural employment (Speare 1971). On contrary, Latin American countries have failed to cross the Lewis turning point. The economic and social development has got stagnant and great numbers of migrants are concentrated in urban conventional sectors there. Even certain generations' efforts have failed to achieve upward mobility (Borges 2005).

Seymour M. Lipset and Reinhard Bendix (1959) studied the impact of rural migration in industrial society on urban structure of occupation. They found that the expansion of urbanization makes rural labors and urban residents have different motion trend under the same conditions: rural labors become the bottom level in cities, while the local bottom level has the opportunity to move upward on occupation. Peter M. Blau and Otis D. Duncan (1967) have a similar finding in The American Occupational Structure, that rural background migrants are disadvantaged in social economics status and are often found in the lowest occupation category, while the urban resident and migrants from other urban area with good education and skills stacked on the top of rural labors' occupations, and they gained a better occupational status. Hagen Koo (1978) summarized this situation as two models with structural linkage, static underprivileged model and dynamic push-up model. But, he found that certain cases in Asia and Latin America do not support his models. First of all, rural-urban migrants have a strong selectivity. This means that a considerable proportion of rural-urban migrants come from upper-middle-class families in rural society, rather than the imagined low-skilled and low-level groups. They have enough education and resources to compete with urban residents for better occupations. Therefore, the role of rural migration as the bottom of occupation structure is non-existent, and the urban economy in developing countries is usually divided into conventional sectors and modern industrial sectors. Most urban residents are engaged in marginal economic activities, and only a small part of them have relatively good occupations. In other words, the advantages of urban residents are not obvious.

Calvin Goldscheider's research on developing countries also shows that rural labors are less disadvantaged in cities, especially, after a period of migration, there aren't many systematic differences 
(Goldscheider1987) between them and urban residents. Economic motivation is primary in driving rural labors to cities (such as finding non-agricultural jobs or looking for better job opportunities). But migration decisions are based not on actual job vacancies but on potential job opportunities and the willingness of migrants and their family strategies. In essence, rural-urban migration digests the surplus rural labor force and meets the demand of urban economic expansion, which is a process of realizing generational and intergenerational occupational mobility and an important mechanism of national economic integration. Those rural labors are selected who are more skilled and highly motivated to compete with urban residents. Education and skills are essentials for rural labors and urban residents in the formal and informal sector to achieve their occupational attainment. One of the most important factors for rural labors is that they not only fit in the informal sector, but, many of them also get white-collar and blue-collar jobs. Housing of migrants is related to poverty, especially, when new migrants have not yet integrated into the urban economy. In summary, Calvin Goldscheider argues that previous studies have shown that there are no structural factors that prevent new migrants from participating in urban economies. Instead, the new migrants in cities have the opportunity to gain economic and social benefits to integrate well into cities.

Before David Goldscheider and Hagen Koo, some scholars found the rural-urban migrants in Latin American countries, whose selectivity would change along the change of social economic status. On the one hand, the attractive job opportunities in big cities and the population pressure in rural areas as the pull and push factors; on the other hand, the urban development craved for labor force, thus the number of rural labors is increasing and the selectivity is becoming lower (Balan 1969; Browning and Feindt1969; Mangin1967). Low selectivity means rural-urban migration turns from selective pattern to massive pattern. In other words, the selective migration of highly skilled population in rural areas and small towns is expanded to the vast rural areas, including a large number of low-skilled population (Simmons and Cardona 1972). This structural change of selective pattern to population pattern has made it difficult for the large numbers of low-skilled migrants to integrate into the city's economic and social structure, and this change partly explains the deterioration of the socioeconomic status of some Latin American countries.

\section{Domestic Migration Study in China}

Over the past 30 years, China's socioeconomic structure has gradually shifted from an agricultural society to an industrial society. The domestic migration, which being named as "alien population", "floating population" and "temporary resident" is dramatically increasing. In Hukou system, "alien population", "floating population" and "temporary resident" are statistical indices to non-local population census. Still naming the migrants as "floating" or "temporary" is inaccurate because a large number of these people are de-facto residents ( $\mathrm{Li}$ 2007). These inaccurate concepts make people focus on the mobility of non-local population while neglecting its residency. Therefore, this paper uses "non-local population" to refer to the settled migrants who took part in urban economic activities but were registered as non-local in Hukou system. Academics has been paying attention to the living conditions, adaptation process and social demands of the migrant population in the city, as well as the administrative policy towards the migrant population, especially on migrants' salary, social welfare, working environment, social security, civil rights, identity transformation and other aspects of urban public services. Different disciplines attend its various perspectives: economics focuses on the cause and scale of the rural surplus labor transfer; sociology emphasizes the living conditions of non-local population; demography studies the age, gender and other demographic characteristics of the migrant population, and the law of change; while anthropology focuses on the cultural adaptation, social organization, group relationship and ethnic identity of non-local population (Zhou et al 2007, 3-17). This section of the paper focuses on the classification of non-local population and the characteristics of each sub-group, the stratification and its influence on social strata in cities.

Gu Shengzu (1989) and Li Debin (1993) categorized China's domestic migration to economic migration and non-economic migration. Economic migration refers to the migrants who participate directly in urban economic activities, including "any non-local laborer contracted or temporarily hired in 
any trade in a city", vendors or peddlers who buy or sell farm or industrial product, and craftsmen from rural area. Non-economic migration refers to the migrants who temporary stay in cities for family visit, sightseeing tour or business trip. In this section, we only consider the economic migration as our research object, excluding the non-economic migration. Economic migration population can be segmented into: industrial laborer who participate in industry, construction and logistics; agricultural laborer who participate in planting, breeding and animal husbandry; businessmen who participate in business management or trade, service providers who participate in catering, commerce or repair; and casual laborer who drift frequently among trades. The high-profile rural labor is the major part of the non-local labor force which initially refers to temporary labor contracted to the state-own or collective-own industrial enterprise -mostly in construction, mining and manufacturing sector- engaged in manual labor, on the contrary to the permanent staff under the planned economy (Gong 1988; Zhu 1988).

Early studies regarding rural labor mostly focus on the rural labor flowing to industrial enterprises (Yang 1995). Gradually, the concept of "rural labor" became a label for all migrants from rural areas to cities (Chen 2005). Academics use the concept of rural labor generally referring to the people conducting manual or business activities in cities from rural areas (Li 1999; Wang and Qin 2002), or even the whole non-local population ( $\mathrm{Li}$ and Tang 2002). In fact, the economic transformation and social structure adjustment along with the rapid influx of rural migration cause expansion and class stratification of migrants. The non-local population in cities is now divided into three distinct social strata: the business owners who possess large capital and employ others; the self-employed individuals who possess small capital and conduct small businesses; and the dependent employees who live mostly on salary (Li 1996). As early as 1991, We noticed the reality of social stratification among the non-local population and conducted a series of surveys on the sub-group of "causal laborer". Causal laborer refers to those migrant workers who engage in various "freelance" occupations; they have neither individual business certificates nor they are official employee in some enterprise (Zhou 1994). Li Peilin's research on urban villages shows that the term migrant is not limited to the dimension of presence or absence of capital, but it also encompasses the difference of level of education and skill (Li 2002). Specifically, the non-local population is divided into: a. self-employed small business owners engaged in various commercial and service industries; $b$. the working class who lives entirely on salary, and it can be subdivided into: 1 . "white-collars" are generally technicians, marketing personnel, teachers, doctors, taxi drivers, editors, journalists, company clerk and other occupations; 2. "blue-collars" are generally processing and manufacturing workers, construction and decoration industry employees, catering, logistics and other service sector employees, casual laborer. "Rural labor" is a generalized concept. "It cannot be regarded as a static and intrinsic concept, but only a relative concept, temporarily established by its subject -identified by the hukou status- under a specific relationship of recognition and exclusion" (Wang 2009). The non-local population is all given the "rural" label because they are in a non-resident state; and then labeled as "rural labor".

As far as the aspect of resident/ non-resident is concerned, some scholars proposed the approach of "urbanize rural labor". Liu Chuanjiang (2006) divided China's urbanization process into two stages: a. rural labor migrates to cities and become migrant workers, which is the process of "non-agriculturalization of rural labor"; b. rural labor change to the urban occupation and identity, which is process of "urbanization of rural labor". The urbanization of rural labor includes four aspects: 1. occupation, rural labor transformed from rural labor on the secondary segment of labor market into non-agricultural workers in the primary segment of labor market; 2 . social identity, from peasant to urban resident; 3. improvement of skills, rural labor gain skill and education under the urbanizing process; 4. urbanization of ideology, lifestyle and behavior of rural labor.

The classification and stratification of the "rural labor" hold much importance in the process of urbanization (Gu, et al 2006; $\mathrm{Hu} 2009$ ). In summary, relevant research suggests that rural labor is divided into four categories: 1. entrepreneurs who have large capital and hire others; 2. self-employed business owner who have a small capital; 3. skilled workers; and 4. unskilled workers. The academics pay much attention to "new- age rural labor" or "second generation rural labor" (Wang 2001; Zhang and Lei 2009). Some research works suggest "new-age rural labor" are generally more urban than rural as they are 
neither willing to return to the countryside nor are acclaimed by urban society. Therefore, they are the group most eager to urbanize and be assimilated into the urban society. Some research emphasizes that first two groups have high income, good living conditions and high social status thus making it easy for them to complete the process of urbanization. The urbanization of rural labor is theoretically concerned with the fact that "rural labor transformed to industrial labor". But, still the reality is that the rural labor is highly stratified. The urbanization subject is not only the rural labor but also non-local private entrepreneurs, non-local self-employed businessmen and even non-local white-collar workers. This difference is shown by the self-contradiction present in the words combined for formulation of "urbanize rural labor". It also shows the conceptual expansion of the expression of "rural labor" in the study of migration population (Wang 2007).

\section{Two Narratives and Approaches on China's Domestic Migration Research} The Narrative and Approach of "Rural Labor"

As Jorge Balan (1969) said, in the context of urbanization, "the social composition of the city is determined by the economic development model of a country, especially the socio-economic differences between urban and rural areas". Rural-urban migration studies in other countries show that countries in Europe and North America; countries in East Asia; and Latin American countries have three different urban social structure patterns during the industrialization period: 1. European and North American countries quickly complete their rural-urban migration; the urban economic-social structure completely replicates the rural-urban dual structure, but economic development quickly dispels this difference. 2. Post-developed countries in East Asia have obvious selective rural-urban migration, and the migrants in urban structure tend to be elite. Therefore, there is no obvious systematic difference between rural labors and urban residents. 3. Latin American rural-urban migration is massive; urban economic-social structure is seriously divided; and economic development cannot eliminate the growing differentiation.

In China's planned economy era, the "heavy industry priority" development strategy has caused serious segregation between urban and rural areas. After 1978, the reform and opening-up policy was applied, and the dislocation development of industrialization and urbanization has resulted in "semi-urbanization". This means rural labors cannot achieve urbanization (Wang 2006). As a result, the academics invented the expression of "rural labor" in the study of domestic migration. This expression of "rural labor" emphasizes the recognition that the migrants from rural areas are subject to the institutional restrictions related to their hukou status (Chen 2005). This duplicates the rural-urban dual structure based on hukou system. It contains the following key points: 1. non-local populations are mainly the migrants from rural areas to cities and towns, especially to metropolises; 2 . non-local populations are generally at the bottom of urban society (Zhu 2003b); 3. hukou system and relevant policies are the main barriers for non-local populations to achieve economic and social integration in cities (Li 2009).

Many cases in developing countries show that the rural-urban migration is not the only form of urbanization, whereas, migration from towns and small cities to major cities, and from major cities to metropolis also make important parts of urbanization migration (Simmons and Cardona 1972; Kim 1982, Kemper 1971). As Li Peilin (2002) wrote "migrants are not all from rural areas, but, migration from small cities to major cities, from cities in less-developed areas to cities in developed areas, from economically depressed cities to economically blooming cities is becoming common." Otherwise, the stratification of non-local population is a common sense among the academics. Beside the migrants at the bottom of social-economic strata, there are also white-collars and small business-owners who want to "make money and then return to hometown", and those migrants who "already gained social-economic position at middle-class or even higher" (Zhai and Hou 2010). In industrial enterprise, "it is easy for non-local laborer to compete with local laborer and stand out" (Li 2006). Some academics point out that China's domestic migration is an exceptional case where the unique hukou system makes the migrants unable to convert to permanent residents (Zhu 2004). Anyhow, the hukou system does exist or not, the variables and mechanisms difference of the socioeconomic status between locals and non-locals still exist. Therefore, we argue that the studies regarding non-local population and related policies based on the origins -rural/urban- or identities -hukou definition should be questioned. 
From the perspective of rural-urban dual structure, the academics often discuss the following subjects: whether the rural surplus labor migrate to cities or convert to non-agricultural industries in situ; the population growth in metropolises will be controlled or not; and certain others. Therefore, numerous studies used quantitative method to calculate "the maximum capacity of cities", "the maximum migration allowance", "the social cost to accommodate rural labors in cities" and etc., trying to ease the fears and concerns of the government. We find an interesting phenomenon: when academics make an appeal to improve the status quo of the vulnerable groups, even if the central government responds positively and issues guiding policies with high profile, and the corresponding policies of local governments tend to be obviously conservative. Such methods like "selective urban admittance" and "integrated social welfares" quite deviate from the academics' intention. These policies and corresponding studies are mainly aimed at improving rural labor's temporary living conditions in cities, rather than solving the development problem of a permanent population. Reviewing on 30 years of development, if the government wanted to restrict rural labor from entering the city, they still entered the city; if the government wanted to control the city size, the city has grown and the population has gone beyond the control indicators. "Urbanization is a result of natural selection and it cannot be determined by administrator's will. The level of urban development is a self-determined process of economic development" (Lin 2001). We believe that the study of migrant populations requires a broader and deeper perspective, especially focusing on social transformation and urban integration of new migrants (Massey, et al 1993).

\section{The Narrative and Approach of "Urban Immigrant"}

In recent years, the academics have paid attention to the perspective beyond the urban-rural dual structure, and started to discuss the social adaptation, integration and even residency of the migrant population. Chen Yingfang (2004) has disputed the use of concepts such as "non-local population" and "rural labor", and tried to describe rural labor groups as "new urban immigrant", and defined their rights and interests as "urban resident rights". Zhu Li (2003a) labels migrants as new urban migrants and classifies them as intellectual migrants, capital migrants and labor migrants. Nonetheless, he mainly focuses on the living conditions and social status of labor migrants. Wen Jun $(2005 ; 2006)$ also focuses on the labor migrant, and called it "new labor immigration". The so-called "new labor immigration" refers to the migrants mainly engaged in simple manual labor in cities, but they have obtained fairly stable jobs and fixed residence and are subjectively willing to settle in the city for a long time. Zhang Wenhong and Lei Kaichun $(2008 ; 2009)$ also regarded the migrant population as urban new immigrants, and they mainly studied the white-collar new immigrants among them. Li Wei (2005) said "The settlement of new immigrants is not limited to improving the living conditions of migrant workers, but it should extend to the ground of urban settlement and livability, and then enlarging the perspective of promoting China's urbanization, industrialization and modernization".

With the deepening of industrialization, on the one hand, the industry began to transfer in an orderly way, and the industrial development presented a trend of decentralized distribution. On the other hand, metropolis and major cities seek industrial upgrading and develop service economy. With the development of new rural construction, China's urbanization will become increasingly diversified and the occupational differentiation will become more obvious. The social and economic environment nowadays is quite different from the formation background of the expression "rural labor". First, urbanization is accelerating, and urbanization will be the main driving force for economic development in the future. Second, as we learnt from previous research results, the migrant population in big cities is no longer mainly composed by rural labors, and the proportion of the migrant population from city background is increasing. Third, the human capital of the migrant population is very diverse, and the employment is very extensive, from engineers, white-collar workers, to private business-owners, industrial laborer, casual laborer, and so on. Fourth, the strata distribution of migrant population is relatively scattered because of their occupation distribution. Fifthly, it is a fact that migrants have achieved social mobility in cities. Sixth, the hukou system and the segregated social welfare system will continue to exist. Seventh, market reforms have largely dismantled institutional barriers for migrants and helped to strip away institutional benefits. These are the practical foundations for our expression of "urban immigrant". 
We use the concept of "urban immigrant" to describe the study of migrant population in order to get rid of the urban-rural binary opposition thinking, so that our attention is focused on urban society. On the one hand, "urban immigrant" covers urban migrants from different sources and different levels. On the other hand, we regard the division of hukou as a result of the fact of social structure. Therefore, we pay more attention to how the new urban immigrants affect the urban social composition and thus "force" the reform of the system (Li 2008). As mentioned above, "the modernization transformation of urban-rural dual economic and social structure is actually the process of migration". In other words, immigration is a way of social development. The expression of "urban immigrant" provides a sociological interpretation for this development mode (see Figure 1-1). Firstly, the starting point of this process is the expansion and upgrading of the urban economic structure which attracts a large number of populations to the city and promotes regional balance in the sense of location, and then the new urban immigrants through the labor force reproduction to achieve the intergenerational flow of the occupation in the sense of time. Therefore, the local strata structure accepts urban immigrant and realizes the social mobility in the sense of structure. Thus, the urban society was eventually reconstructed.

\section{FIGURE 1 DIAGRAM OF "MIGRATION AS A MODE OF DEVELOPMENT"}

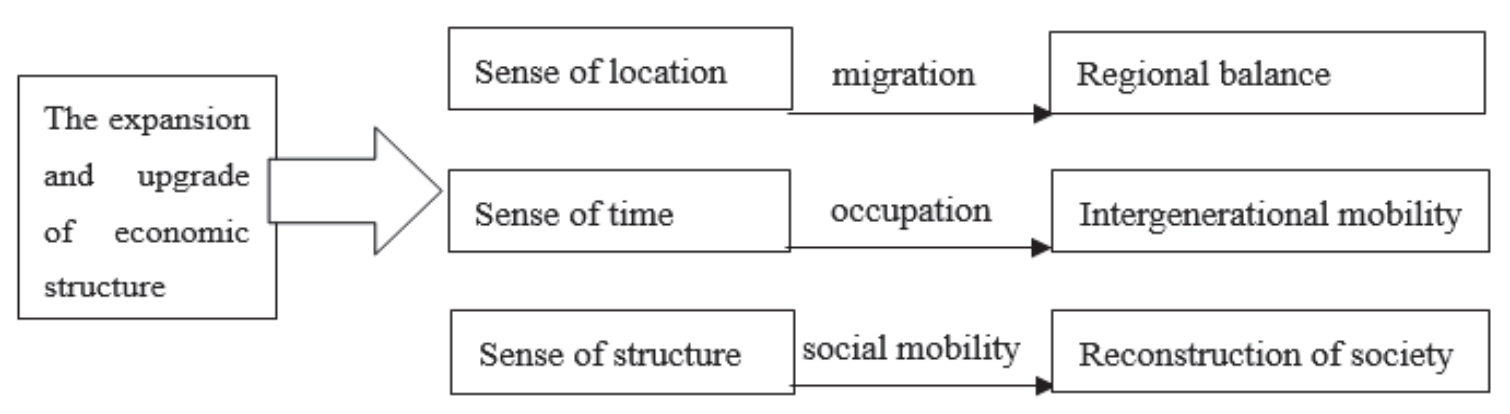

When this macro process of "migration as a mode of development" is implemented at the city level, our perspective focuses on the "social incorporation" of new immigrants in cities (DeWind and Kasinitz1997). The expressions of "social incorporation" and "new immigrants", refer to new immigrant from the same background -such as education- who have the same opportunities as local residents under the same conditions -such as institutional environment, economic environment, etc- to obtain the equality on employment and social strata. Considering there are 200 million immigrants in the China's cities, it is of more practical significance to study the mechanism of immigration and how to promote the integration of these immigrants into urban society. First, the long-term, family and settlement trend of the immigrants in urban society shows that the immigrants have been incorporated into urban society in a certain way and to a certain extent. Secondly, social incorporation is an important way to understand urban social problems and solve urban social problems. Therefore, social incorporation is not only a social process but also an ultimate goal. Thirdly, social incorporation includes economic incorporation and structural incorporation. Economic incorporation refers to that the immigrants have equal opportunities like the local residents to join an occupation with the corresponding background, and realize the generational and intergenerational occupational mobility, thus obtaining the corresponding economic status. Structural incorporation (Gordon 1961) means that the immigrants have sufficient opportunities to have social connections -such as marriage- with local residents of similar social strata after gaining corresponding economic status. For immigrant population, social incorporation enables them to cross the boundary of immigrant communities and eliminate prejudice and discrimination between them and local residents. This process is reflected in the identity proximity and mutual tolerance of cultural customs. For individual immigrants and their families, social incorporation enables the immigrants and the local residents to cross the social space and enhance communication in schools, workplaces and neighborhood. This process is reflected in the reduction of social distance and mutual respect of customs and habits. 
Some Chinese academics often compare "psychology", "culture", "identity" and "customs and habits" with "economic incorporation" while studying the social integration of urban immigrants, and they also pay attention to "the interdependence and interaction between them". According to these studies, relevant foreign theories and experiences emphasize cultural incorporation, as well as "the mutual integration and infiltration of cultures", which puts cultural incorporation in the same position with economic incorporation (Yang 2009; Zhang 2008). Although Gordon has classified social assimilation and acculturation or behavioral assimilation as two processes of integration, his theory of immigrant assimilation, as mentioned by Yang Juhua and Zhang Wenhong, he believes that "once structural integration is achieved, all other kinds of integration will occur". In the United States, owing to the complex race relations, the structural integration of the whole society did not appear, while the intra-racial cultural integration occurred to a large extent (Alba and Nee 1997). In fact, the background of relevant foreign studies is somewhat different from that of China. On the one hand, foreign researches on social integration of immigrants are mostly aimed at international migration-especially migrants from developing countries-and cultural differences based on race. However, the social integration of urban immigrant population in our study did not encounter obvious racial and cultural differences, but cultural differences based on stratification. On the other hand, the international migration studied abroad takes place in the stage of developed industry, while China is in the period of modernization transformation. This paper puts forward the expression of "urban immigrant" in the context of modernization transformation and derives the social integration process in accordance with China's actual situation. Economic incorporation takes place before structural incorporation, while creating conditions for structural incorporation. In our study, cultural differences, as Pierre Bourdieu views it, are the result of "members of different classes being always under the restriction of the respective class, with their particular class fractions, enter the field of different tastes, and choose different ways of life to show their class identity" (Liu 2003). Cultural differences change with the change of the social integration conditions, affecting individuals as well as families and groups simultaneously. To sum up, the expression of "urban immigrant" not only deepens our understanding of the way of social development, but also derives the perspective of "social incorporation" of new urban immigrants. This theoretical turn attempts to put the changes of urban social composition and the structural relationship between immigrants and local residents at the core of the study, laying the foundation for the study of new urban immigrant. Generally speaking, immigration, as a process, can be divided into three stages: first, middle and last. Correspondingly, the question of new urban immigrant also contains three issues: a. What has happened? The basic status of new urban immigrant and its impact on the composition of urban society -such as changes in population structure, labor market and class structure-; b. What should happen? How to define the social integration of cities as an ultimate goal? c. How does urban social integration happen as a process? Immigrants, as the research object, can be cut into the above three topics from the macro, meso and micro perspectives. Therefore, in the actual research, there is not only macroscopic argumentation, but it also involves the influence of meso and micro variables. This makes the empirical research on the new urban immigrant issue more colorful.

Meanwhile, In the narrative and approach of urban immigration study, the long-term and sustainable social integration of immigrants shall be closely monitored. As international migration study shows, the first generation or the first and half generation (Rumbaut 1994) of immigrants are the beginning of social integration, which set the research background of our urban immigration study. Large-scale urban immigration in China has only been happening for three decades, although "the new generation of immigrants" and "the second Generation of immigrants" have attracted academic attention, China's situation is not exactly the same as that of the new generation of immigrants studied and discussed abroad (Hirschman 1994). Most of the early immigrants in China did not settled, and most of the new generation of immigrants with the intention of settling down can only be counted as the first generation of immigrants, and the social integration process of urban immigrants has just begun. However, the trend of urban settling, the increasingly obvious trend of immigrant household, and the intergenerational reproduction of immigrants in the city all show a good beginning of urban social integration (Lieberson 
1973). Therefore, we must pay attention to the dissolution of urban-rural dual structure in a relatively long period.

\section{CONCLUSION}

Scholars have suggested that China is entering the era of migration and the urban immigrants should be accommodated (Liang 2001), "immigrants who are willing to settle and thrive in cities should be accepted and eventually integrate into urban society" (Ren and Wu 2004). Three decades is not a long period for immigration integration, and it is a good time for the academics to expand the research on which. On the one hand, we must be aware of the rural-urban dual structure which formalized by the hukou system, and further impact on the urban resident-immigrant binary opposition, had a profound influence on research thinking and data analyzing, as in urban social mobility research "caused serious sampling bias (Wu 2007)". On the other hand, we have to admit rural labor or floating population is not a phenomenon subject to China only, by promoting the narrative of "urban immigrant" instead of "rural labor", we suggest the migration studies on developing or late-developed countries shall be brought to the attention (Wang and Zuo 1999), as well as taking reference on developed countries' experience and theories, in a sense of disciplinary development of migration sociology or anthropology (Waters 1999). Therefore, focus our research on the immigration and integration in urban society which being neglected and accumulated for thirty years.

This paper emphasis the narrative and approach of "urban immigrant", which regard the immigration as a way of social development. This narrative and approach focus on the urban social strata reconstitution caused by immigration; thus, the final picture of the reconstitution is an urban-rural binary harmony. This idea puts the structural relationship between immigrants and native residents at the core of the research, it shall not be seen as a macroscopic perspective, but also both medium and microscopic perspectives may apply on particular cases, which can track social psychology and group interaction to social strata. The exploration on the fore mentioned subjects will help us discover the true characteristics of China's urban society during this transition period and enlighten us the truth about urban social integration.

\section{ENDNOTES}

1. Hukou is a system of household registration in mainland China, it is a complex social control method affect Chinese livelihood in many ways, it is necessary to comprehend this concept before reading this paper.

2. "Central First Document" is issued by the politburo of CCP yearly, usually on the beginning of a year, is a guidance document of the whole year's policy.

3. In "The American Occupational Structure" (p.272), Blau and Duncan also discussed similar immigration selectivity. (in any case) "immigrants would gain higher professional status and achieve upward flow more easily than non-immigrants". We see this as an immigration characteristic of the United States as a developed industrial society, different from the immigration selectivity of developing countries.

4. The article refers to the case of the new generation: "it is unacceptable to identify themselves as rural migrant, and rural migrant should refer to those who do manual work in building houses at the construction site, but they are vague about their hukou, social security and other issues". This case expresses the tension of the concept.

5. A large part of the social mobility of the migrant population is a form of transformation within the external system, which cannot be noticed in the context of "rural migrant". 


\section{REFERENCES}

Alba, R., \& Nee, V. (1997). Rethinking Assimilation Theory for a New Era of Immigration. International Migration Review, 31(4), 826-874.

Balan, J. (1969). Migrant-Native Socioeconomic Differences in Latin American Cities: a Structural Analysis. Latin American Research Review, 4(1), 3-29.

Blau, P. M., \& Duncan, O. D. (1967). The American Occupational Structure. New York: Wiley.

Borges, M. G. (2005). Citizenship for the Urban Poor? Inclusion trough Housing Program in Rio De Janeiro, Brazil. Ph.D. dissertation, the University of Colorado.

Browning, H. L., \& Feindt, W. (1969). Selectivity of Migrants to a Metropolis in a Developing Country: A Mexican Case Study. Demography, 6(4), 347-357.

Chen, Y. (2005). Peasant-labor: System and Identity. Sociological Research, 3, 119-132.

Chen, Y. (2004). Focus on Urban Immigrant (A Public Speech). Jiefang Daily, August 22.

Department of the State. (2003). Guidance on policies regarding increase rural population's income. China Government Web Site. Retrieved July 17, 2019, from http://www.gov.cn/gongbao/content/2004/content_63144.htm.

Department of the State. (2006). The outline of the eleventh five-year plan for national economic and social development of the People's Republic of China. China Government Web Site. Retrieved July 17, 2019, from http:/www.gov.cn/gongbao/content/2006/content_268766.htm.

DeWind, J., \& Kasinitz, P. (1997). Everything Old is New Again? Processes and Theories of Immigrant Incorporation. International Migration Review, 31(4), 1096-1111.

Goldscheider, C. (1987). Migration and Social Structure: Analytic Issues and Comparative Perspectives in Developing Nations. Sociological Forum, 2(4), 674-696.

Gong, Y. (1988). Recruit Permanent Labor, Replace Rural Labor, Nanjing Nitrogen Fertilizer Factory Tap the Potential of Labor. People's Daily, August 17.

Gordon, M. M. (1961). Assimilation in America: Theory and Reality. Daedalus, 90(2), 263-285.

Gu, S. (1989). A Study on Population Migration. Wuhan University Journal (Social Science Edition), 2, 44-49.

Gu, S., Yi, S., \& Zheng, L. (2006). Sustainable Development of Industrialization and Urbanization in China: An Approach Based on the Characteristics of Rural Migrant Workers. Population Research, 5, 1-8.

Hirschman, C. (1994). Problems and Prospects of Studying Immigrant Adaptation from the 1990 Population Census: From Generational Comparisons to the Process of 'Becoming American'. International Migration Review, 28(4), 690-713.

Hu, C. (2009). Urbanization of Migrant Workers Should Pay Attention to Classified Guidance. Guangming Daily, November 13.

Kemper, R. V. (1971). Rural-Urban Migration in Latin America: A Framework for the Comparative Analysis of Geographical and Temporal Patterns. International Migration Review, 5(1), 36-47.

Kim, H-K. (1982). Social Factors of Migration from Rural to Urban Areas with Special Reference to Developing Countries: The Case of Korea. Social Indicators Research, 10(1), 29-74.

Koo, H. (1978). Rural-Urban Migration and Social Mobility in Third World Metropolises: Across-National Study. The Sociological Quarterly, 19(2), 292-303.

Lee, E. S. (1996). A Theory of Migration. Demography, 3(1), 47-57.

Lewis, W. Arthur.1954. "Development with Unlimited Supplies of Labor. Manchester School of Economic and Social Studies, 22(2), 139-191.

Li, D. (1993). The Characteristics and Causes of Migration in Contemporary China. Sociological Studies, 4, 65-73.

Li, P. (2008). Modernity and Chinese Experience. Society, 3, 2-6.

Li, P. (1996). Rural Migrant's Social Network and Status. Sociological Research, 4, 42-52.

Li, P. (2002). Tremendous Changes: The End of Villages, A Study of Villages in the Center of Guangzhou City. Social Sciences in China, 1, 168-179. 
Li, P., \& Chen, G. (2009). New Growth Stage of China's Development: Analysis and Forecast of China's Social Development Situation from 2009 to 2010. Social Science Archive Press.

Li, Q. (1999). The Occupational Mobility of Rural Migrant in Cities of Mainland China. Sociological Research, 3, 9.

Li, Q., \& Tang, Z. (2002). Rural Migrant and Informal Employment in Cities. Sociological Research, 6, 13-25.

Li, R. (2009). Urban White-collar Group: Analysis on Guangzhou Population Data. Chinese Journal of Population Science, 2, 84-92.

Li, R. (2007). A Preliminary Analysis of the Settlement and Mobility of the Migrant Population in Guangdong Province. Demography Study, 6, 45-54.

Li, R. (2006). The Opportunities and Obstacles for Status Attainment: An Analysis of Occupational Structure in Communities with Dense Floating Population. Chinese Journal of Population Science, 5, 69-78.

Li, W. (2005). Residential Urbanization: A Perspective on Sciences of Human Settlements. Higher Education Press.

Liang, Z. (2001). The Age of Migration in China. Population and Development Review, 27(3), 499-524. Lieberson, S. (1973). Generational Differences among Blacks in the North. American Journal of Sociology, 79(3), 550-565.

Lin, Y. (2001). Rural Modernization and Urban Development. China Financial News, August 17. Lipset, S. M., \& Bendix, R. (1959). Social Mobility in Industrial Society. Berkeley: University of California Press.

Liu, C. (2006). A Study of Urbanization of Rural Migrant in China. Theory Monthly, 10, 5-12.

Liu, X. (2003). Class Habits and Tastes: Bourdieu's Class Theory. Sociological Research, 6, 33-42.

Lu, X. (2009). China's Population Facing Situation of Trisection. People Website. Retrieved July 5, 2019, from http://politics.people.com.cn/GB/1027/9129924.html.

Mangin, W. P. (n.d.). Latin American Squatter Settlements: A Problem and a Solution. Latin American Research Review, 2(3), 65-98.

Massey, D. S., Arango, J., Hugo, G., Kouaouci, A., Pellegrino, A., \& Taylor, J. E. (1993). Theories of International Migration: A Review and Appraisal. Population and Development Review, 19(3), 431-66.

Mercer, B. E. (1969). Rural Migration to Urban Settings: Educational and Welfare Problems. International Migration Digest, 2(1), 52-62.

National Census Bureau. (2009). Digest of Statistics in 2009. Beijing: China Statistics Press.

Northam, R. M. (1975). Urban Geography. New York: John Wiley \&Sons.

Ravenstein, E. G. (1876). The Birthplace of the People and the Laws of Migration. The Geographical Magazine, 3, 173-177, 201-206, 229- 233.

Ravenstein, E. G. (1889). The Laws of Migration. Journal of the Royal Statistical Society, 52(2), 241-305.

Ravenstein, E. G. (1885). The Laws of Migration. Journal of the Statistical Society of London, 48(2), $167-235$.

Ren, Y., \& Wu, M. (2006). Social Integration of Urban Floating Population: A Research Review. Population Research, 3, 87-94.

Rose, A., \& Warshay, L. (1957). The Adjustment of Migrants to Cities. Social Force, October, 72-76.

Rumbaut, R. G. (1994). The Crucible within: Ethnic Identity, Self-Esteem, and Segmented Assimilation among Children of Immigrants. International Migration Review, 28(4), 748 - 794.

Simmons, A. B., \& Ramiro, C. G. (1972). Rural-Urban Migration: Who Comes, Who Stays, Who Returns? The Case of Bogotá, Columbia, 1929-1968. International Migration Review, 6(2), 166-181.

Speare, A., Jr. (1971). A Cost-Benefit Model of Rural to Urban Migration in Taiwan. Population Studies, 25(1), 117-130.

Todaro, M. P. (1969). A Model of Labor Migration and Urban Unemployment in Less Developed Countries. The American Economic Review, 59(1), 138-148. 
Wang, C. (2006). A Study of Floating People’s ‘Semi-urbanization’. Sociological Studies, 5, $107-122+244$.

Wang, C. (2001). The Social Identity of New Generation Rural Migrant and the Relationship with Rural-urban Integration. Sociological Research, 3, 63-76.

Wang, D., \& Wei, Q. (2002). A Study on Intergenerational Difference of Rural Migrant: Comparative Stratification of Rural Migrant in Chengdu. Population Research, 5, 49-54.

Wang, F., \& Zuo, X. (1999). Inside China's Cities: Institutional Barriers and Opportunities for Urban Migrants. The American Economic Review, 89(2), 276-280.

Wang, X. (2009). From "Existence" to "Recognition": Issues of Peasant Workers in the View of Citizenship. Sociological Research, 1, 121-138.

Wang, Y. (2007). A Sociological Study on Urbanization of New Generation Rural Migrant. China Youth Study, 5, 38-41.

Waters, M. C. (1999). Sociology and the Study of Immigration. American Behavioral Scientist, 42(9), 1264-1267.

Wen, J. (2005). The System Composition and Behavior Preference of New Urban Immigrant in China. Social Sciences in Nanjing, 1, 54-58.

Wen, J. (2006). Are They Migrant or Resident? A Study on Shanghai's New Labor Migrant Since1980s. In Modern Awareness and Urban Studies, edited by Propaganda department of CPC Shanghai Municipal Committee, 32-67. Shanghai People's Publishing House.

Wu, X. (2007). The Hukou System and Inter-generation Occupation Mobility. Sociology Research, 6, 38-65, 242-243.

Yang, H. (1995). An Investigation on Pearl River Delta’s "Rural Labor Rush. Demography Studies, 2, 53-56.

Yang, J. (2009). From Isolation and Selection to Integration: Theoretical Contemplating on Integration of Immigrant. Population Research, 1, 17-29.

Zhai, Z., \& Jiawei, H. (2010). Migrant Population Concentrated Communities in Beijing: Patterns and Trends. Population Research, 1, 30-42.

Zhang, W., \& Lei, K. (2008). The Urban New Immigrants' Social Inclusion: Internal structure, present situation and influential factors. Sociological Studies, 5, 117-141, 244-245.

Zhang, W., \& Lei, K. (2009). Structural Equation Model of the Social Identifications of the New Urban Immigrant. Sociological Studies, 4, 61-87, 243-244.

Zhang, Z. (2009). Intergenerational Urbanization of Rural Migrant: A Comparative Study Based on Multiple Employment of Rural Migrant. Jianghan Tribune, 11, 117-120.

Zhou, D. (1994). A Study on Migrant Casual Labor in Guangzhou. Sociological Research, 4, 47-55.

Zhou, D. (2005). Longing for Survival: An Anthropology Observation on Rural Labor's Mobility. Sun Yat-Sen University Press.

Zhou, D. (2017). Study on Chinese Migrant Workers for Thirty Years: My Personal Exploration. China Agricultural University Journal of Social Sciences Edition, 6, 60-67.

Zhou, D., Zhou, J., \& Liu, Z. (2007). Free Urban Marginal People - Study on Casual Laborer in Southeast Coast of China. Sun Yat-Sen University Press.

Zhou, T. (2009). The Hesitation, Missteps and Consequences of China's Urbanization Progress. Cities Reviews, 1, 5-23.

Zhu, L. (2003a). How to Recognize Rural Migrant, Preface. In New Urban Immigrant: Report On Immigrant of Nanjing, edited by Zhu Li and Chen Ru. Nanjing University Press.

Zhu, L. (2003b). Characteristics and Social Status of the Peasant Worker Class. Journal of Nanjing University (Philosophy, Humanities and Social Sciences), 6, 41-50.

Zhu, L. (1988). Pros and Cons of Massive Rural Labor Recruit by Enterprises. Shanghai Enterprise, 8, 42-43.

Zhu, Y. (2004). Overseas Research on Non- permanent Migration and Its Implications for the Issues of Floating Population in China. Population Research, 3, 52-59. 